\title{
Differential sensitivity of different discrimination behaviors to the effects of ethanol*
}

\author{
FRANK A. HOLLOWAY and RICHARD A. WANSLEY \\ Department of Psychiatry and Behavioral Sciences \\ University of Oklahoma Health Sciences Center \\ Oklahoma City, Okla. 73190
}

A dose-response analysis of the effects of ethanol on various aspects of successive discrimination performance in rats was made to assess any differential sensitivity of such behaviors to the effects of the drug. At least four sequential phases of the drug's effect on performance were indicated: (a) a general and significant facilitatory effect on all response measures at the $0.5-\mathrm{g} / \mathrm{kg}$ dose, (b) no significant effect on any behavior at the $1.0-\mathrm{g} / \mathrm{kg}$ dose, (c) a significant depression of responding on $\mathrm{S}+$ trials and during the intertrial interval concomitant with continued facilitation of responses on $S-$ trials at the $1.5 \mathrm{-g} / \mathrm{kg}$ dose, and finally (d) a depression of all response measures at the $2.5 \mathrm{~g} / \mathrm{kg}$ dose. These data were discussed in terms of a model in which ethanol depresses operant response inhibitory processes at lower dose levels than it depresses processes involved in response initiation or execution.

Previous investigations (Holloway \& Vardiman, 1971; Holloway \& Wansley, 1973) have confirmed the existence of a "biphasic" effect of ethanol (Mello, 1968) on various operant behaviors of rats, where low doses increased and high doses decreased the level of operant responding with either fixed-ratio or DRL (differential reinforcement of low rates of responding) schedules of reinforcement. It was suggested that response inhibitory processes were somehow more vulnerable to the effects of ethanol than were processes associated with response execution. The increase in responding with low doses was thought to be due to this disinhibitory effect of ethanol. However, these previous studies could not distinguish any general excitatory effect of low doses of ethanol from effects specifically related to response inhibition.

Generally, ethanol apparently reduces the suppression of instrumental approach responding of rats in situations where such suppression was induced by extinction procedures (Barry, Wagner, \& Miller, 1961), by punishment of the approach response (Grossman \& Miller, 1961), or by novel aspects of the experimental chamber (Barry et al, 1961; Schalock \& Wollen, 1966). In pigeons, relatively low doses of ethanol increased overall rates of responding for food reward and increased the number of responses to a nonrewarded visual stimulus (Blough, 1956).

Dews (1955) has shown that the disruption of discrimination performance by drugs such as pentobarbital or methamphetamine was attributable to increases in responding to the nonreinforced

*This research was supported in part by Public Health Service Grant MH-14702 awarded to the senior author's project at the Oklahoma Center for Alcohol-Related Studies. discriminative stimuli (S-). Terrace (1963) has also noted that when responding to the $\mathrm{S}-$ in a discrimination task is gradually suppressed as a function of erroneous responding and accompanying nonreinforcement, certain drugs produced increases in responding to the $\mathrm{S}-$. Yet, these same drugs had no such effect on responses to the $S$ - when the discrimination was learned by an errorless training procedure in which nonreinforcement and subsequent response inhibition were never associated with the $\mathrm{S}-$.

In the present investigation, the dose-response effects of ethanol on asymptotic successive discrimination performance were examined. In the particular task employed, the effects of ethanol on three classes of responding could be examined: (a) responses during the intertrial interval (ITI), (b) responses to the discriminative stimuli $(\mathrm{S}+)$ which resulted in reinforcement, and (c) responses to the $\mathrm{S}-$ which did not result in reinforcement. If these different behaviors were differentially sensitive to ethanol, their dose-response curves should reveal such differences.

\section{METHODS \\ Subjects}

The Ss were eight 90-day-old male albino rats (Sasco Co., Holtzman-derived strain), ranging in weight from 275 to $320 \mathrm{~g}$ at the beginning of the experiment. All animals were housed in individual cages with ad lib water and were maintained at $80 \%$ of their basal body weight (determined in a 10 -day period prior to deprivation).

\section{Apparatus}

All Ss were trained by operant shaping procedures to press a lever for 45-mg Noyes food pellets in a standard Skinner box (Lehigh Valley No. 143-28). All animals were maintained on a 12-h light (0800-2000 h), 12-h dark (2000-0800 h) schedule and were trained and tested the same time each day between the hours of 1000 and 1400. This apparatus was located in an illuminated, sound-attenuated, and ventilated enclosure. The discriminative stimuli were three horizontally arranged white cue lights $\left(1 / 2\right.$ in. in diam) located $2 \frac{1}{2}$ in. above the lever and 1 in. (center to center) apart.

\section{Procedure}

All animals initially received five daily 30 -min training sessions during which response-contingent reinforcement was available on a fixed-ratio schedule of three responses for one food pellet. This initial fixed-ratio schedule was employed in order to establish a history of responding prior to later discrimination training. All animals then began daily 30 -min training sessions on a simple discrimination task. In this task, response-contingent reinforcement was available intermittently for 10 -sec periods, which were indicated by the cue lights. In order to reduce intertrial responding, the interval between trials (i.e., stimulus periods) was variable, but never shorter than $20 \mathrm{sec}$. Each new trial occurred $20 \mathrm{sec}$ after the animal's last response. Responses before the completion of this 20 -seco period reset a clock which timed an additional $20-\mathrm{sec}$ period before the next trial. A response during the stimulus period delivered one reinforcement and terminated the cue light, while failure to respond meant that 
Table 1

Effects of Ethanol on Discrimination Performance

\begin{tabular}{|c|c|c|c|c|c|c|c|}
\hline \multirow{2}{*}{$\begin{array}{c}\text { Ethanol } \\
\text { Dose } \\
(\mathrm{g} / \mathrm{kg})\end{array}$} & \multirow[b]{2}{*}{ Statistics } & \multicolumn{3}{|c|}{$\mathrm{S}+/ \mathrm{S}-$} & \multicolumn{3}{|c|}{ Number of $S+$ Trials } \\
\hline & & $\begin{array}{c}\text { Saline } \\
\text { (D1) }\end{array}$ & $\begin{array}{c}\text { Ethanol } \\
\text { (D2) }\end{array}$ & $\begin{array}{c}\text { Saline } \\
\text { (D3) }\end{array}$ & $\begin{array}{c}\text { Saline } \\
\text { (D1) }\end{array}$ & $\begin{array}{c}\text { Ethanol } \\
\text { (D2) }\end{array}$ & $\begin{array}{c}\text { Saline } \\
\text { (D3) }\end{array}$ \\
\hline 0.5 & $\begin{array}{l}\text { Meant } \\
\text { SD }\end{array}$ & $\begin{array}{l}3.77 \\
0.94\end{array}$ & $\begin{array}{l}2.31 * * \\
0.70\end{array}$ & $\begin{array}{l}4.49 \\
1.14\end{array}$ & $\begin{array}{r}34.2 \\
4.6\end{array}$ & $\begin{array}{c}29.2^{*} \\
4.0\end{array}$ & $\begin{array}{r}33.6 \\
6.0\end{array}$ \\
\hline 1.0 & $\begin{array}{l}\text { Mean } \\
\text { SD }\end{array}$ & $\begin{array}{l}3.61 \\
0.89\end{array}$ & $\begin{array}{l}3.33 \\
1.41\end{array}$ & $\begin{array}{l}3.96 \\
1.06\end{array}$ & $\begin{array}{r}34.2 \\
4.7\end{array}$ & $\begin{array}{r}33.7 \\
3.2\end{array}$ & $\begin{array}{r}34.8 \\
5.3\end{array}$ \\
\hline 1.5 & $\begin{array}{l}\text { Mean } \\
\text { SD }\end{array}$ & $\begin{array}{l}4.16 \\
0.95\end{array}$ & $\begin{array}{l}2.61^{*} \\
0.92\end{array}$ & $\begin{array}{l}4.58 \\
0.57\end{array}$ & $\begin{array}{r}32.5 \\
2.4\end{array}$ & $\begin{array}{r}35.0 \\
5.7\end{array}$ & $\begin{array}{r}35.2 \\
2.2\end{array}$ \\
\hline 2.0 & $\begin{array}{l}\text { Mean } \\
\text { SD }\end{array}$ & $\begin{array}{l}3.69 \\
0.78\end{array}$ & $\begin{array}{l}1.97 * * \\
0.98\end{array}$ & $\begin{array}{l}4.26 \\
0.67\end{array}$ & $\begin{array}{r}32.0 \\
6.4\end{array}$ & $\begin{array}{c}36.7^{*} \\
3.7\end{array}$ & $\begin{array}{r}33.3 \\
7.2\end{array}$ \\
\hline 2.5 & $\begin{array}{l}\text { Mean } \\
\text { SD }\end{array}$ & $\begin{array}{l}5.09 \\
0.58\end{array}$ & $\begin{array}{l}1.93 * * \\
0.81\end{array}$ & $\begin{array}{l}5.07 \\
0.60\end{array}$ & $\begin{array}{r}37.6 \\
0.5\end{array}$ & $\begin{array}{r}40.4 \\
2.2\end{array}$ & $\begin{array}{r}37.3 \\
1.6\end{array}$ \\
\hline
\end{tabular}

+Repeated-measures analysis of variance (Days 1 and 2, dose level). Probability of saline-ethanol difference: ${ }^{*} p<.05,{ }^{* *} p<.01$.

the animal had to wait an additional $20 \mathrm{sec}$ without responding before the next trial occurred. Under this schedule, an absolute maximum of 90 reinforcement opportunities or trials was possible during the 30 -min session. For one group of animals $(\mathrm{N}=4)$, the cue $(\mathrm{S}+)$, indicating available reinforcement during the stimulus period, was the onset of the center cue light, while the onset of the two outside cue lights provided the $S+$ for the other group of animals $(\mathrm{N}=4)$. Training on this task continued until the animals obtained at least 50 reinforcements in one 30-min session.

After meeting the previous performance criterion, all animals began a series of daily 30-min sessions on a successive discrimination ("go-no go") task. The experimental parameters for this task were identical to those for the previous task, except that there were approximately equal numbers of S+ trials ("go" periods during which response contingent was available) and S - trials ("no go" periods during which no reinforcement was available). As in the earlier training conditions, the intertrial interval was variable, depending on the animal's behavior. The animal had to wait at least $20 \mathrm{sec}$ without responding in order for the next $\mathrm{S}+$ or $\mathrm{S}-$ trial to begin. Responses during either an $\mathrm{S}+$ or $\mathrm{S}-$ period terminated the trial. A film programmer determined the occasion of an $\mathrm{S}+$ or $\mathrm{S}-$ for a particular trial. The center cue light was the $\mathrm{S}+$ for the group previously receiving training with the center light, and the two peripheral cue lights provided the $S+$ for the group with prior experience with these stimuli. The $S-$ condition for both groups was the alternate cue condition: Group $1, \mathrm{~S}+$ (one cue light), $\mathrm{S}-$ (two cue lights); Group 2, S+ (two cue lights), S- (one cue light). Such a design would control for any differential unconditional response tendencies (either increases or decreases) to the presence of one or two stimulus lights.

During the latter discrimination sessions, the following behavioral measures were recorded: number of $S+$ and $S-$ trials, number of intertrial interval responses (ITI-Rs), percent responses to $S+(\% S+R s)$, percent responses to $S-(\% S-R s)$, latency of responding to an $S+$, latency of responding to an $S-$, and finally, the ratio of $\% \mathrm{~S}-\mathrm{Rs}$ to $\% \mathrm{~S}+\mathrm{Rs}(\mathrm{S}+/ \mathrm{S}-)$. When the $\mathrm{S}+\mathrm{S}-$ ratio reached 3.0 , indicating three times as many responses on $\mathrm{S}+$ as on $\mathrm{S}-$ trials, the animals began a series of drug testing sessions. Each week, the animals received a 3-day series of 30-min discrimination sessions: Day 1, saline; Day 2, ethanol; and Day 3, saline.

All animals received a random sequence of ethanol doses $(0.5$, $1.0,1.5$, and $2.0 \mathrm{~g} / \mathrm{kg}$ ) during the first 4 weeks of drug testing. During the final week of drug testing, all animals received a $2.5 \mathrm{~g} / \mathrm{kg}$ dose of ethanol. Each animal received one block of saline-ethanol-saline sessions at each dose level. The ethanol solution was prepared on a $10 \%$ weight-volume basis in normal saline and was injected intraperitoneally (IP) $15 \mathrm{~min}$ prior to the experimental session. On saline days, a volume equivalent to that week's ethanol dose was injected IP. Previous work in our laboratory (Holloway \& Wansley, 1973) had indicated that range of effective blood ethanol levels for the $0.5-\mathrm{g} / \mathrm{kg}$ dose was $31-38 \mathrm{mg} / \mathrm{dl}$, for the $1.5-\mathrm{g} / \mathrm{kg}$ dose was $122-139 \mathrm{mg} / \mathrm{dl}$, and for the $2.5-\mathrm{g} / \mathrm{kg}$ dose was $183-205 \mathrm{mg} / \mathrm{dl}$. Under these injection and deprivation procedures, the peak alcohol level occurred 15-45 min after the IP injection.

\section{RESULTS}

Since there were no significant differences between Groups 1 and 2 (having opposite cue conditions) on any baseline or drug days for any behavioral measure, the data from these groups were combined in all analyses. The effects of ethanol on discrimination performance as indicated by the $\mathrm{S}+/ \mathrm{S}-$ ratio are seen in Table 1 . The lowest dose $(0.5 \mathrm{~g} / \mathrm{kg})$ of ethanol impaired discrimination performance, as did the three highest doses $(1.5,2.0$, and $2.5 \mathrm{~g} / \mathrm{kg})$. The bimodal nature of the effects of various doses of ethanol on discrimination suggests that low and high doses may be affecting different aspects of performance.

The effects of ethanol on total responses and on ITI responses in particular can be seen in Fig. 1 (A and B). The lowest ethanol dose increased responding while the higher dose decreased responding. Since the amount of ITI responding influenced the number of trials one animal received for a session, the effects of ethanol on this trial measure were determined. Since there were no baseline differences in number of $\mathrm{S}+(\overline{\mathrm{X}}=34.1)$ and $\mathrm{S}-$ $(\overline{\mathrm{X}}=34.2)$ trials, only the data for number of $\mathrm{S}+$ trials per session were examined. These data also are presented in Table 1. As can be seen, the low dose of ethanol decreased the number of trials, presumably because higher response rates under this dose resulted in extended ITI periods (due to resetting of the 20 -sec ITI clock). Higher doses of ethanol resulted in an increase in $\mathrm{S}+$ trials over that seen on saline days. This effect may be attributed to the general reduction in responding with higher doses of ethanol; such a decrease would shorten the ITI and permit more trials during the 30 -min session. The effects of ethanol or responding during the S+ 
and $\mathrm{S}-$ trials can be seen in Fig. 1 (C and D). Ethanol doses of $1.5 \mathrm{~g} / \mathrm{kg}$ or higher significantly reduced $\% \mathrm{~S}+\mathrm{Rs}$. The effect of ethanol on the $\% \mathrm{~S}-\mathrm{Rs}$ measure was an increase in responding at the $0.5-$ and $1.5 \mathrm{-g} / \mathrm{kg}$ dose levels, followed by a significant decrease in responding on $\mathrm{S}-$ trials only at the $2.5 \mathrm{-g} / \mathrm{kg}$ dose level. These results, together with those for the ITI-Rs measure, suggest that ethanol facilitates responding at low dose levels and depresses responding at higher dose levels. Additionally, however, it appears that ethanol may have at least two disinhibitory effects on performance in the present experiment. First, a general disinhibition or facilitation of all responding is apparent at the $0.5-\mathrm{g} / \mathrm{kg}$ dose level; ITI-Rs and \%S-Rs were increased, while further increases in the $\% \mathrm{~S}+\mathrm{Rs}$ measure were precluded by a ceiling effect. Secondly, ethanol's apparent disinhibition of responding to the $\mathrm{S}-$ can be seen at a higher dose $(1.5 \mathrm{~g} / \mathrm{kg})$ than the drug's disinhibitory effects on ITI responding $(0.5 \mathrm{~g} / \mathrm{kg})$.

In an attempt to dissociate any generalized disinhibitory effects of ethanol on responding from those disinhibitory effects specific to responding to the $\mathrm{S}-$, the effects of ethanol on S+ and S- latencies were examined; these also are presented in Fig. 1 (E and F). As can be seen, the $0.5-\mathrm{g} / \mathrm{kg}$ dose of ethanol decreased the latency of responding for both S+ and S- trials, but the magnitude of this reduction was significantly greater for $\mathrm{S}-$ trials than for $\mathrm{S}+$ trials $(\mathrm{t}=3.11, \mathrm{df}=7, \mathrm{p}<.02)$. Furthermore, the latency of responding to the S+ was significantly increased at the $1.5 \mathrm{~g} / \mathrm{kg}$ dose level, while a similar increase in $\mathrm{S}$ - latencies was not apparent until the $2.0-\mathrm{g} / \mathrm{kg}$ dose level.

\section{Reversal Discrimination Learning}

In an attempt to clarify the action of the ethanol on response inhibitory processes, the effects of daily injections of $1.5 \mathrm{~g} / \mathrm{kg}$ of ethanol or an equivalent volume of saline on the acquisition of reversal discrimination was examined. Such a procedure simply required the animal to suppress its responses to stimuli previously reinforced (the original $\mathrm{S}+$ ) and to respond to the stimuli previously not reinforced (the original $\mathrm{S}-$ ). After the completion of the drug discrimination study, this study was begun. The four animals receiving saline acquired criterion performance $(S+/ S-=3.0)$ on the average in 15.0 days, while the ethanol animals required an average of 19.3 days (one 30-min training session per day). This difference was significant at the 0.025 level of confidence, using a two-tailed Mann-Whitney U procedure. This difference in acquisition of the reversal discrimination was attributable completely to the ethanol animals' difficulty in suppressing their responses to the previously reinforced stimuli. The mean number of days to reach a criterion of $33 \%$ or lower responses to the new S- was 14.7 days for the saline group and 19.1 days for the ethanol group (Mann-Whitney U probability $=.025$ ). The mean number of days to acquire a criterion of $90 \%$ or higher responses to the new S+ was 10.7 days
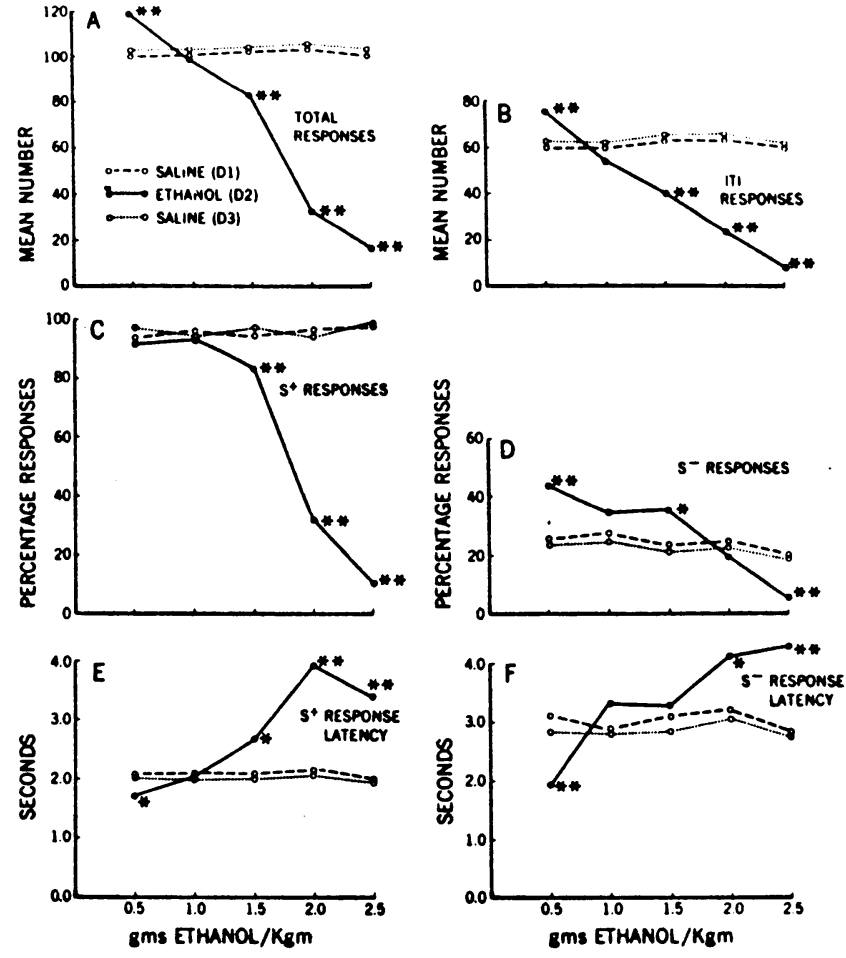

Fig. 1. Dose-response effects of ethanol on behavior (A-F). Repeated measures analysis of variance (Days 1 and 2, dose level). Probability of saline-ethanol difference: ${ }^{*} p<.05$, $* *<.01$.

for the saline group and 11.5 days for the ethanol group (no significant difference). Additionally, there were no overall differences in number of ITI responses between the ethanol and saline groups. These data, together with those for the discrimination study proper, strengthen the interpretation that the increases in responding produced by lower doses of ethanol may be attributable to an impairment of response suppression or inhibitory processes.

\section{DISCUSSION}

Generally, these data indicate that lower ethanol doses increase operant responding and shorten response latencies, while higher doses decrease responding and lengthen response latencies, a finding similar to those reported previously (Holloway \& Vardiman, 1971). In the present experiment, the dose-response effects of ethanol on responding during the ITI period, the $S+$ trials, and the $S-$ trials were not identical. The facilitation of ITI and S+ responding was apparent at only the $0.5-\mathrm{g} / \mathrm{kg}$ dose level, while depression of these measures was noted at the $1.5-\mathrm{g} / \mathrm{kg}$ and all higher dose levels of ethanol. In the case of $\mathrm{S}$ - responding, not only was the ethanol-induced increase in $\mathrm{S}$ - responding still evident at the $1.5 \mathrm{-g} / \mathrm{kg}$ dose level, but also a significant depression of $S$ - response measures was not found until the $2.0-$ or $2.5-\mathrm{g} / \mathrm{kg}$ dose levels were used. Such data certainly indicate that the lower dose facilitatory effects of ethanol are not general, i.e., being manifest on all response measures at every dose level. It also would appear that responding during the ITI was more vulnerable to the suppressive effects of the higher doses of ethanol than was responding on $\mathrm{S}$ trials. Previous work in our laboratory (Holloway \& Wansley. 1973) has indicated that responding controlled by external cues was not reduced at ethanol doses which significantly reduced responding in a similar noncued operant task. Such a parameter 
may have permitted the differentiation of the facilitatory effects of ethanol on ITI and S- response measures.

One could argue that the low ethanol dose was affecting the animal's discrimination capacities per se. thus producing more responding. While this is possible, one would have to postulate a nonmonotonic effect of ethanol on discrimination capacities since the $\mathrm{S}+/ \mathrm{S}$ - ratio was significantly depressed at the 0.5 - and $1.5-\mathrm{g} / \mathrm{kg}$ dose levels but not at the $1.0 \mathrm{-g} / \mathrm{kg}$ dose level. Other investigations have found no effects of ethanol at doses between 0.5 and $1.0 \mathrm{~g} / \mathrm{kg}$ on brightness discrimination (Moskowitz, 1967) or time discrimination (Laties \& Weiss, 1962; Holloway \& Wansley, 1973). Such data suggest that a purely sensory explanation for the low dose impairment is unlikely. Furthermore, although the baseline rates for ITI responding were relatively high and those for $\mathrm{S}$ - responding were relatively low. the $0.5-\mathrm{g} / \mathrm{kg}$ dose produced an increase in both measures. To more specifically address the issue of response disinhibition, reversal discrimination acquisition was examined under conditions of $1.5 \mathrm{~g} / \mathrm{kg}$ ethanol or an equivalent volume of saline. Since this dose reduced ITI responding but enhanced $\mathrm{S}$ responding, one would expect that this dose of ethanol would impair acquisition of the reversal discrimination specifically by impairing the animal's ability to suppress its responses to the previously reinforced stimuli. The latter outcome was obtained and was significant even with a relatively small number of Ss.

The present data suggest that behavioral processes involved in response suppression or inhibition are more vulnerable to the effects of ethanol than are those processes concerned with response initiation or execution. Other data show that passive avoidance learning is impaired at an ethanol dose level, which does not affect the acquisition of an active avoidance response (Holloway, 1972). While such data supports a low-dose disinhibition hypothesis, the precise nature of those mechanisms underlying the differential sensitivity of different operant behaviors to the effects of ethanol awaits further behavioral and pharmacological specification.

\section{REFERENCES}

Barry, H., III, Wagner, S. A., \& Miller, N. E. Effects of ethanol and amobarbital on performance inhibited by experimental extinction. Journal of Comparative \& Physiological Psychology, 1962, 55, 464-468.

Blough, D. S. Technique for studying the effects of drugs on discrimination in the pigeon. Annals of the New York Academy of Sciences, 1956, 65, 334-344.

Dews, P. B. The effects of pentobarbital, methamphetamine, and scopolamine on performances in pigeons involving discriminations. Journal of Pharmacology \& Experimental Therapeutics, 1966,115, 380-389.

Grossman, S. P., \& Miller, N. E. Control of stimulus change in the evaluation of alcohol and chlorpromazine as fear-reducing drugs. Psychopharmacologia, 1961, 2, 342-351.

Holloway, F. A. State-dependent effects of ethanol on active and passive avoidance learning. Psychopharmacologia (Berlin), $1972,25,238-261$.

Holloway, F. A., \& Vardiman, D. R. Dose-response effects of ethanol on appetitive behaviors. Psychonomic Science, 1971, 24, 218-220.

Holloway, F. A., \& Wansley, R. A. Factors governing the vulnerability of DRL operant performance to the effects of ethanol. Psychopharmacologia (Berlin), 1973, 28, 351-362.

Laties, V. G., \& Weiss, B. Effects of alcohol on timing behavior. Journal of Comparative \& Physiological Psychology, 1962, 55, 85-91.

Mello, N. K. Some aspects of the behavioral pharmacology of alcohol. In D. H. Efron et al (Eds.), Psychopharmacology: A review of progress, 1957-1967. PHS Publication No. 1836. Washington, D.C: U.S. Government Printing Office, 1968. Pp. 787-809.

Moskowitz, H. The effect of alcohol upon the differential brightness threshold. Psych opharmacologia (Berlin), 1967, 10, 354-360.

Sauerland, E. K., Knauss, T., \& Clemente, C. D. Effects of ethyl alcohol on orbital-cortically induced reflex inhibition in the cat. Brain Research, 1967, 6, 164-180.

Schalock, K. M., \& Wollen, K. A. The immediate and long-term effect on runway performance of reversing ethanol and dextrose conditions. Psychonomic Science, 1966, 4, 113-114.

Terrace, H. S. Errorless discrimination learning in the pigeon: Effects of chlorpromazine and imipramine. Science, 1963, $140,318-319$.

(Received for publication June 13, 1973.) 